Review

\title{
Toward a structure-based comprehension of the lectin pathway of complement
}

\author{
Troels R. Kjaer ${ }^{\mathrm{a}}$, Steffen Thiel ${ }^{\mathrm{a}}$, Gregers R. Andersen ${ }^{\mathrm{b}, *}$ \\ a Department of Biomedicine, Aarhus University, Wilhelm Meyers Allé 4, DK-8000 Aarhus, Denmark \\ ${ }^{\mathrm{b}}$ Department of Molecular Biology and Genetics, Aarhus University, Gustav Wieds Vej 10C, DK-8000 Aarhus, Denmark
}

\section{A R T I C L E I N F O}

\section{Article history:}

Received 2 May 2013

Accepted 14 May 2013

\section{Keywords:}

Complement system

Pattern recognition

MBL

MASP

Protease activation

C4

Structural biology

\begin{abstract}
A B S T R A C T
To initiate the lectin pathway of complement pattern recognition molecules bind to surface-linked carbohydrates or acetyl groups on pathogens or damaged self-tissue. This leads to activation of the serine proteases MASP-1 and MASP-2 resulting in deposition of C4 on the activator and assembly of the C3 convertase. In addition MASP-3 and the non-catalytic MAp19 and MAp44 presumably play regulatory functions, but the exact function of the MASP-3 protease remains to be established. Recent functional studies have significantly advanced our understanding of the molecular events occurring as activation progresses from pattern recognition to convertase assembly. Furthermore, atomic structures derived by crystallography or solution scattering of most proteins acting in the lectin pathway and two key complexes have become available. Here we integrate the current functional and structural knowledge concerning the lectin pathway proteins and derive overall models for their glycan bound complexes. These models are used to discuss cis- versus trans-activation of MASP proteases and the geometry of C4 deposition occurring on glycans in the lectin pathway.
\end{abstract}

(c) 2013 Elsevier Ltd. All rights reserved.

\section{Introduction}

Many immunological mechanisms have evolved to defend the body toward infections and for maintenance of homeostasis in the body. Thus many cells and molecules are taking part in the anti-microbial defence systems and at the same time are involved in the removal of apoptotic or necrotic cells and tissue components. The complement system is an integral part of the innate immune system formed by more than 50 proteins. Its activation triggers a proteolytic cascade eliciting a number of immunological effector functions including the enhancement of phagocytosis, the recruitment of inflammatory cells, the formation of pores in membranes and further an instructive role on a following adaptive immune response (Ricklin et al., 2010). Complement may be activated through the alternative, the classical, and the lectin pathways, here we focus on activation through the lectin pathway (LP). The principal players of the LP are the recognition molecules: the collectins mannan-binding lectin (MBL), collectin K-1 (CL-K1), and the three ficolins (H-ficolin, L-ficolin and M-ficolin) (Fig. 1). Associated with these are three proteases: the MBL associated serine proteases (MASPs) MASP-1, MASP-2 and MASP-3 and the two MBL associated proteins MAp19 (also known as sMAP) and MAp44 (also called MAP-1) (Yongqing et al., 2012).

\footnotetext{
* Corresponding author. Tel.: +45 871555 07; fax: +45 86123178 .

E-mail address: gra@mb.au.dk (G.R. Andersen).
}

\section{The pattern recognition molecules}

MBL and CL-K1 belongs to the collectin family, a family also encompassing the surfactant proteins of the lung (SP-A and SP-D), collectin L-1 (CL-L1, also named collectin 11) and the membrane bound long placental collectin-P1 (CL-P1) (Veldhuizen et al., 2011). Collectins are characterized by a collagen-like region and a C-type carbohydrate recognition domain (CRD) in their C-terminal end (Fig. 2A). Such a C-type CRD specifically recognizes a monosaccharide exposing horizontal $3^{\prime}$ - and $4^{\prime}-\mathrm{OH}$ groups, i.e. as in glucose and mannose and in $\mathrm{N}$-acetyl-glucosamine. The affinity for the monosaccharide is very weak (mM range) and only when ligands are organized in a pattern fitting with simultaneous binding of several CRDs will strong binding (nM range) of the collectins to the pattern occur.

In humans three ficolins exist, $\mathrm{H}$-ficolin (also named Hakataantigen or ficolin-3), L-ficolin (also named p35 or ficolin-2) and $\mathrm{M}$-ficolin (also named p35-related protein or ficolin-1) whereas only two, equivalent to L- and M-ficolin, are found in mice and rats. Similar to the collectins the polypeptide chain of ficolins contains a short N-terminal and a collagen-like domain, but in this case the C-terminal recognition domain is a fibrinogen-like domain (FBG) instead of the CRD domain. The FBG has affinity for N-acetylated carbohydrate structures in general, e.g. as in GlcNAc, but will also bind other acetylated molecules, e.g. acetylated-albumin or acetylated glycine. As for the collectins a strong binding only occurs when several FBG domains simultaneously interact with acetyl groups in a fitting pattern. Both MBL and the ficolins associate 


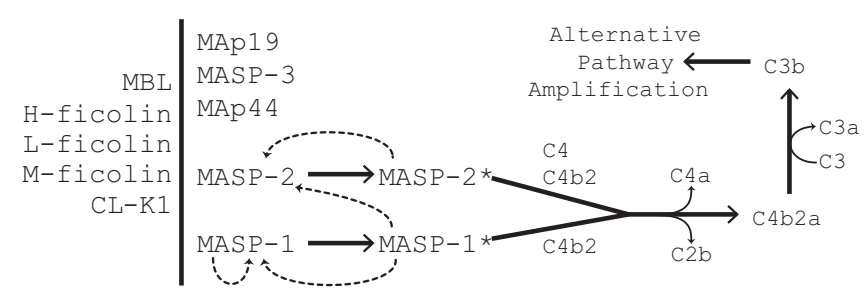

Fig. 1. The lectin pathway of complement activation. MBL, ficolins and CL-K1 are associated with MASP-1, MASP-2, MASP-3, MAp44 and MAp19. Upon recognition of distinct patterns on a surface, the associated zymogen MASP-1 and MASP-2 are activated (dashed arrows). Zymogen MASP-1 can auto-activate and activate zymogen MASP- 2 resulting in active forms, i.e. MASP- $1^{*}$ and MASP- $2^{*}$. The activated forms can activate more zymogens. Activated MASP-2 cleaves $\mathrm{C} 4$ and $\mathrm{C} 2$ in association with C4b (C4b2), whereas MASP-1 only cleaves C2 in the C4b2 complex. These activities result in the assembly of the $\mathrm{C} 3$-convertase $\mathrm{C} 4 \mathrm{~b} 2 \mathrm{a}$ on the surface, which cleaves $\mathrm{C} 3$. The anaphylotoxin $\mathrm{C} 3 \mathrm{a}$ is released, and $\mathrm{C} 3 \mathrm{~b}$ is bound to the surface where it participates in the alternative pathway amplification loop. MASP-3 and MAp44 competes with MASP-1 and MASP-2 for the same binding sites on, e.g. MBL and may thus inhibit lectin pathway activation.

into homotrimers that further oligomerize as described in details below for MBL. The ficolins and MBL and CL-K1 associate with the MASPs and are thus able to activate the lectin pathway complement cascade upon recognition of a suitable pattern (Yongqing et al., 2012).

\subsection{Mannan-binding lectin}

MBL was the first protein described to be able to initiate the lectin pathway, in this case on surfaces composed of constituents of Saccharomyces cerevisiae, i.e. mannan. The composition and structural organization of MBL will be discussed in detail below, but the overall organization means that many CRDs are present in the fully assembled MBL molecule (Fig. 2C). Several of these recognition domains must simultaneously bind to a pattern ligand to obtain strong binding of MBL and lectin pathway activation. Such patterns are presented by bacteria, e.g. Escherichia coli and Staphylococcus aureus, on viruses, e.g. Influenza A virus and HIV and on fungi, e.g. Cancida albicans and S. cerevisiae, as previously reviewed (Thiel and Gadjeva, 2009). Recognition of altered self or damaged self is an important function of the immune system, and binding of MBL to apoptotic cells has been described and may facilitate clearance of such altered cells (Nauta et al., 2003; Stuart et al., 2005).

MBL serum concentrations range from a few $\mathrm{ng} / \mathrm{ml}$ to more than $10 \mu \mathrm{g} / \mathrm{ml}$, with a mean value of around $0.8 \mu \mathrm{g} / \mathrm{ml}$ and strongly correlates with the genotypes of the MBL2 gene. Common single nucleotide polymorphism (SNPs) in the promoter region and exon 1 of the MBL2 gene mirrors the variations in MBL serum concentrations, and MBL deficiency is quite common (Steffensen et al., 2000), and several studies indicate an association between disease and deficiency of MBL (Moller-Kristensen et al., 2009). In plasma $\mathrm{MBL}$ is found in complexes with the three serine proteases of the lectin pathway MASP-1 (Matsushita and Fujita, 1992), MASP-2 (Thiel et al., 1997) and MASP-3 (Dahl et al., 2001), and with the two associated proteins MAp19 (Stover et al., 1999; Thiel et al., 1997) and MAp44 (Degn et al., 2009). Apart from the complement activating abilities of the MBL/MASP complexes interactions of MBL with membrane bound proteins has been described as well, e.g. interaction with complement receptor 1 (CR1, CD35) (Ghiran et al., 2000; Jacquet et al., 2013; Tenner et al., 1995), with the chaperone calreticulin (Pagh et al., 2008) and with the low-density lipoprotein receptor-related protein CD91 (Duus et al., 2010). Such interactions may facilitate engulfment of apoptotic cells as seen via a calreticulin/CD91 complex by macrophages (Ogden et al., 2001).

\subsection{Collectin-K1}

CL-K1 (also named collectin sub-family member 11 or CL-11) resembles MBL in structure. The $34 \mathrm{kDa}$ polypeptide chain of CL-K1 forms trimeric structural subunits via disulphide bridges between one cysteine in the $\mathrm{N}$-terminal and two cysteines near the neck region and these homotrimers form larger oligomers (Hansen et al., 2010; Keshi et al., 2006). Human CL-K1 binds to mannose and fucose in a calcium dependent manner (Keshi et al., 2006), and to different microorganisms such as E. coli, C. albicans and Pseudomonas aeruginosa (Hansen et al., 2010), Streptococcus pneumoniae (Ali et al., 2012) and to LPS from E. coli and Klebsiella pneumoniae (Keshi et al., 2006). CL-K1 is able to interact with MASP-1 and MASP3 (Hansen et al., 2010), MASP-2 and MAp44 (Ali et al., 2012; Ma et al., 2013) and is able to mediate complement activation on $C$. albicans (Ma et al., 2013). CL-K1 is localized in the kidney, adrenal gland and liver but is also present in plasma at $2 \mu \mathrm{g} / \mathrm{ml}$ (Hansen et al., 2010).

\subsection{H-ficolin}

$\mathrm{H}$-ficolin was the first of the human ficolins to be discovered (Inaba et al., 1990) and present in human serum with a median concentration of around $20 \mu \mathrm{g} / \mathrm{ml}$ (Krarup et al., 2005). It is assembled from a $35 \mathrm{kDa}$ polypeptide chain forming trimeric structural subunits that again forms larger oligomers of various sizes (Yae et al., 1991). H-ficolin binding toward acetylated structures has been observed (Garlatti et al., 2007a; Zacho et al., 2012), but despite this reactivity only very few microorganisms bind $\mathrm{H}$-ficolin, emphasizing that although binding to simple molecules may be observed there is a demand for a correctly positioned pattern to allow for strong binding. Binding of $\mathrm{H}$-ficolin to the capsular polysaccharides from Aerococcus viridans (Tsujimura et al., 2001) and lipopolysaccharides from Hafnia alfvei (Swierzko et al., 2012) or from other bacteria (Salmonella typhimurium, Salmonella minnesota and E. coli) (Sugimoto et al., 1998) has been observed. A neutralizing activity of Influenza A virus have been seen, but not though binding of the FBG domain (Verma et al., 2012). H-ficolin is also able to bind altered self-surfaces, e.g. on apoptotic, late apoptotic and necrotic cells and might subsequently mediate clearance via interactions with calreticulin (Honore et al., 2007; Kuraya et al., 2005). A number of studies have presented associations between patient cohorts and genotypes of the $\mathrm{H}$-ficolin encoding gene FCN3 and protein levels of $\mathrm{H}$-ficolin. There are thus reports on patients lacking $\mathrm{H}$-ficolin due to a frameshift mutation in the FCN3 gene (Munthe-Fog et al., 2009; Schlapbach et al., 2011).

\subsection{L-ficolin}

The L-ficolin polypeptide of $35 \mathrm{kDa}$ polypeptide chain forms trimeric structural subunits which oligomerizes primarily into complexes above $250 \mathrm{kDa}$ (Krarup et al., 2004; Matsushita et al. 1996). The estimated serum and plasma L-ficolin concentration in normal individuals is around $5 \mu \mathrm{g} / \mathrm{ml}$ (Krarup et al., 2005). The FBG of L-ficolin has the broadest ligand specificity of the ficolins. It was found to bind to acetylated molecules, e.g. GlcNAc or GalNAc (Le et al., 1998) and various other acetylated glycans (Krarup et al., 2008) but also non-carbohydrate compounds, e.g., N-acetyl cysteine (CysNAc) and N-acetyl glycine (GlyNAc) (Krarup et al., 2004). L-ficolin binds to numerous pathogen associated molecular patterns, such as $\mathrm{N}$-glycans of the hepatitis $\mathrm{C}$ virus envelope glycoproteins (Liu et al., 2009), and lipoteichoic acid (LTA) (Lynch et al. 2004). L-ficolin has a broad affinity for microorganisms and parasites, e.g. S. typhimurium TV119, S. aureus, S. pneumoniae (Krarup et al., 2005), Trypanosom cruzi (Cestari Idos et al., 2009), Mycobacterium bovis (Carroll et al., 2009), Giardia intestinalis (Evans-Osses 
A

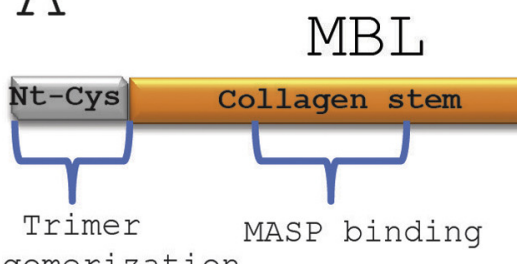

oligomerization

MASP binding

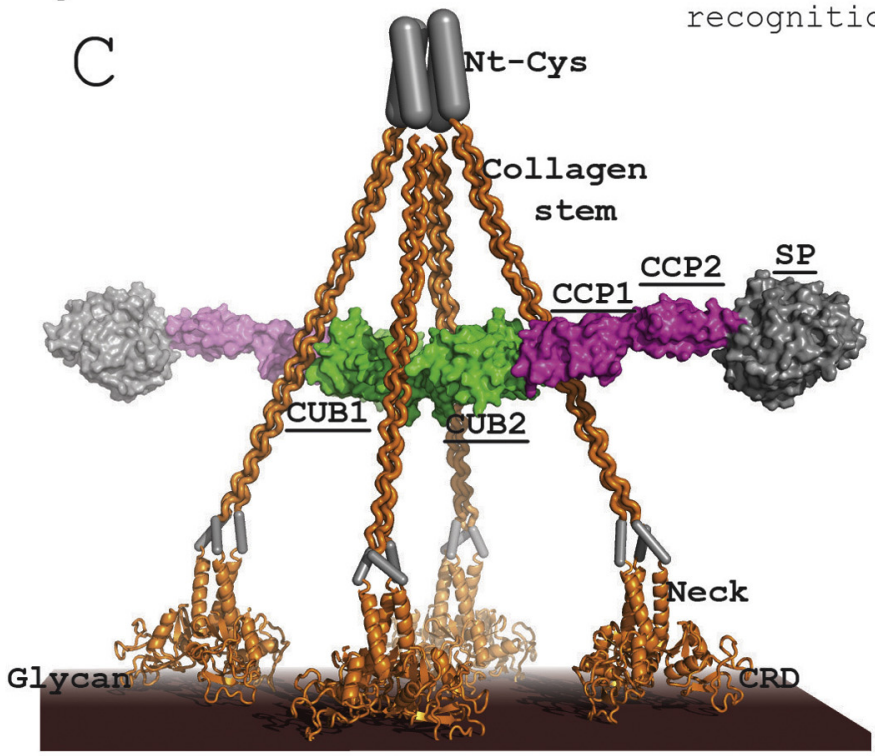

B

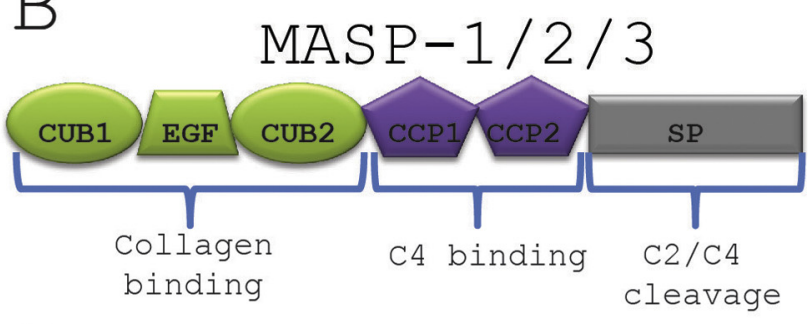

$\mathrm{D}$
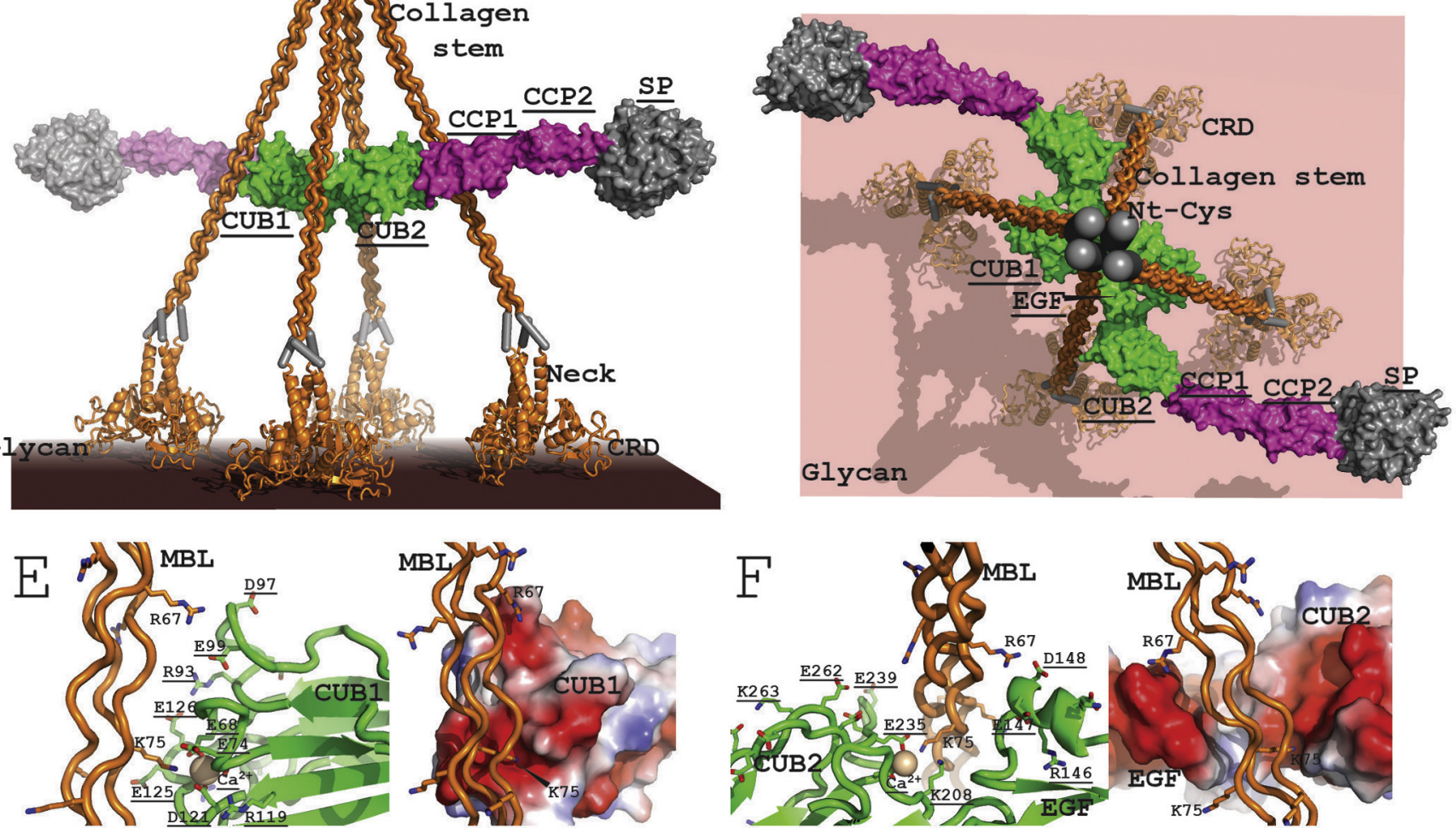

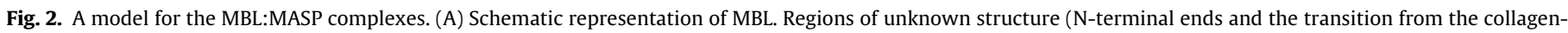

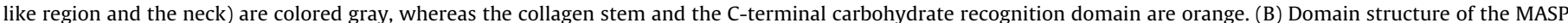

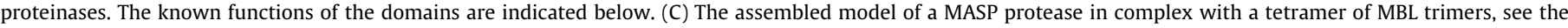

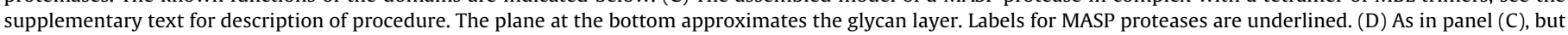

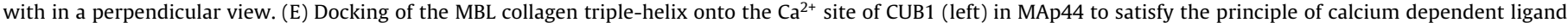

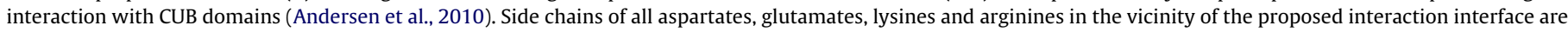

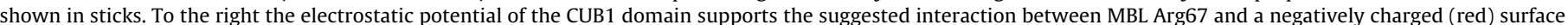

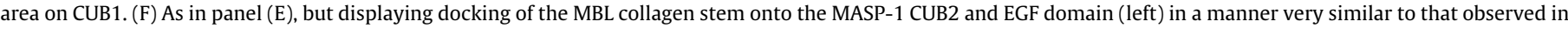

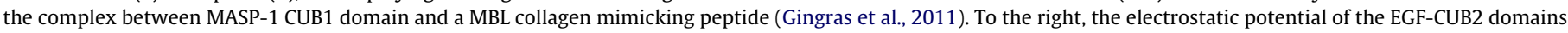
reveals a very acidic environment for accommodation of MBL Arg67 and possibly a Lys75 not involved in CUB2 interaction.

et al., 2010) and Aspergillus fumigatus (Ma et al., 2009). Binding of L-ficolin to Streptococcus agalactiae (group B streptococci) has been suggested to be via the acetyl groups in sialic acid in the capsular polysaccharides (Aoyagi et al., 2005, 2008) although in our hands this is not the case (Kjaer et al., 2011). Like MBL and Hficolin, L-ficolin also binds apoptotic and necrotic cells, and may help to mediate their clearance presumably via an interaction with calreticulin (Kuraya et al., 2005; Moller-Kristensen et al., 2007).

\subsection{M-ficolin}

The $34 \mathrm{kDa}$ polypeptide chain of M-ficolin forms the trimeric structural subunit which oligomerizes into $250 \mathrm{kDa}$ complexes (Lu et al., 1996; Wittenborn et al., 2010). In serum M-ficolin is present at $0.5 \mu \mathrm{g} / \mathrm{ml}$ (Kjaer et al., 2013) and elute as a $\sim 900 \mathrm{kDa}$ complex in gel permeation chromatography, which is a significant larger complex compared to L- and H-ficolin (Wittenborn et al., 2010). M-ficolin is the only recognition molecules of the lectin pathway not produced in the liver. Instead it is mainly produced by peripheral blood leukocytes and bone marrow cells (Harumiya et al., 1996; Lu et al., 1996) and due to this it is also found on the surface of these cells (Honore et al., 2010; Kjaer et al., 2011). Its interaction with the host cell surfaces has been attributed to binding to sialic acid residues (Honore et al., 2010), to association of the FBG domain with a G-protein coupled receptor (GPCR 43) (Zhang et al., 2010) or binding to leukosialin (CD43) (MorenoAmaral et al., 2012). M-ficolin binds to a variety of N-acetylated monosaccharides, such as GlcNAc, GalNAc and sialic acids (Gout et al., 2010; Teh et al., 2000). With respect to microorganisms S. aureus, S. typhimurium (Liu et al., 2005), group B streptococci 
(Kjaer et al., 2011) and S. pneumoniae (Kjaer et al., 2013) are bound by M-ficolin.

\section{Mannan-binding lectin associated serine proteases and proteins}

The most well-established role of the recognition molecules is their association with five MBL associated serine proteases and proteins originating from two genes. MASP-1, MASP-3 and MAp44 are alternative splice products from the MASP1 gene (Dahl et al., 2001; Degn et al., 2009; Takada et al., 1993), while MASP-2 and MAp19 are alternative splice products from the MASP2 gene (Stover et al., 1999). MASP-1, -2 and -3 contain two CUB, one EGF, two CCP and the catalytic SP domain (Fig. 2B). The C-terminal SP domain is connected to the CCP2 domain via a linker peptide (also known as the activation peptide). Upon activation of the MASP, an Arg-Ile bond in the activation peptide is cleaved, and the resulting $A$-chain (corresponding to CUB1-EGF-CUB2-CCP1-CCP2 and the linker) and B-chain (i.e. the SP domain) are covalently connected through a disulfide bond (Sato et al., 1994).

\section{1. $M A S P-1$}

MASP-1 probably evolved early and MASP-2 and MASP-3 of the lectin pathway, together with $\mathrm{C} 1 \mathrm{r}$ and $\mathrm{C} 1 \mathrm{~s}$ from the classical pathway, are believed to originate from an ancestral MASP-1 like gene (Nonaka and Miyazawa, 2002; Sato et al., 1994). MASP-1 is primarily synthesized in the liver and is present at $11 \mu \mathrm{g} / \mathrm{ml}$ in plasma (Thiel et al., 2012). MASP-1 was initially suggested to cleave both C2 and C4 (Matsushita and Fujita, 1992), but C4 cleavage was later disproven (Rossi et al., 2001; Thiel et al., 1997), and MASP-1 can therefore not initiate the lectin pathway on its own (Fig. 1). Direct C3 cleavage has also been proposed (Matsushita and Fujita, 1995), although the rate of the activity seems non-physiological (Rossi et al., 2001). However, MASP-1 has a decisive role in the lectin pathway (Fig. 1) as it cleaves zymogen MASP-2 to activated MASP-2 and $\mathrm{C} 2$ in the proconvertase $\mathrm{C} 4 \mathrm{~b} 2$ thereby generating the $\mathrm{C} 3$-convertase C4b2a (Chen and Wallis, 2004; Degn et al., 2012; Heja et al., 2012; Megyeri et al., 2013; Moller-Kristensen et al., 2007). The activation of MASP-1 itself occurs through auto-activation (Ambrus et al., 2003), and this may be a major control step of the whole activation process of the lectin pathway (Megyeri et al., 2013). Recently a role for MASP-1 in activation of the alternative pathway of complement was described. Factor $D$, the serine protease cleaving factor $B$ within the alternative pathway, was only present in an inactive proform in masp1 knockout mice lacking MASP-1, MASP-3 and MAp44 (Takahashi et al., 2010). However, in humans the MASP1 gene products are not required for alternative pathway activity (Degn et al., 2012). Other protease activities have been observed for MASP-1, which may be a quite promiscuous enzyme, but usually only seen at rather high enzyme concentrations and after long incubation times (Dobo et al., 2011; Yongqing et al., 2012).

\section{2. $M A S P-2$}

MASP-2 is synthesized in the liver and is present at $0.4 \mu \mathrm{g} / \mathrm{ml}$ in plasma (Ytting et al., 2007). In contrast to MASP-1 MASP-2 is a very specific protease which very efficiently cleave $\mathrm{C} 4$ and proconvertase $\mathrm{C} 2$, thus with the ability to generate the $\mathrm{C} 3$ convertase on its own (Rossi et al., 2001; Thiel et al., 1997). MASP-2 can auto-activate (Vorup-Jensen et al., 2000), but under physiological conditions, MASP-1 is the essential MASP-2 activator (see above and Fig. 1). MASP2 knockout mice lack a functional lectin pathway which grants these mice protection against ischemia reperfusion injuries (Schwaeble et al., 2011) but also susceptibility toward infections with S. pneumoniae (Ali et al., 2012) and West Nile virus
(Fuchs et al., 2011). Humans lacking MASP-2 activity has been described but the clinical effect is not fully understood (Olesen et al., 2006; Stengaard-Pedersen et al., 2003). Based on the frequency of the mutation resulting in deficiency, such cases should in principle be present in $1 / 10,000$ individuals in the general White European population.

\section{3. $M A S P-3$}

A clear cut catalytic activity on a physiological relevant substrate remains to be proven for MASP-3 but recent reports on the involvement of mutations in the MASP-3 serine protease encoding part of the MASP1 gene in patients with the 3MC syndrome (a developmental disorder) support an important activity of the enzyme during development (Rooryck et al., 2011; Sirmaci et al., 2010). There are conflicting observations regarding MASP-3 autoactivation. The human proform does not seem to auto-activate (Zundel et al., 2004), but mouse MASP-3 might auto-activate when associated to MBL bound to a bacterial ligand (Iwaki et al., 2011). As for mouse MASP-1, mouse MASP-3 is suggested to be involved in activation of the alternative pathway via cleavage of factor $D$ and B directly (Iwaki et al., 2011; Takahashi et al., 2010), but such an activity does not seem to be essential in humans (Degn et al., 2012).

MASP-3 may attenuate the lectin pathway activity due to competition for MASP binding sites on the recognition molecules (Degn et al., 2009).

\subsection{MAp19 and MAp44}

MAp19, the small alternatively spliced fragment from the MASP2 gene contains only the first CUB1 and the EGF domain together with 4 unique amino acids (Stover et al., 1999; Thiel et al., 1997). The concentration of MAp19 in serum is $0.2 \mu \mathrm{g} / \mathrm{ml}$ (Degn et al., 2011) and the protein was originally suggested to have a regulatory role on the lectin pathway activation (Stover et al., 1999). The use of MAp19 knockout mice supports a modulating role of MAp19, although this is only evident under non-physiological conditions (Iwaki et al., 2006). An attenuating role of MAp19 on lectin pathway activation is not observed in humans under more physiological conditions (Degn et al., 2009). Interestingly, MAp19 is excreted in urine and may inhibit calcium oxalate crystal growth, suggesting a role in inhibition of renal stones (Kang et al., 1999). MAp44 is an alternatively spliced product of the MASP1 gene comprising the common CUB1EGF-CUB2-CCP1 domains and in addition 17 amino acids not shared with MASP-1 or MASP-3 (Degn et al., 2009; Skjoedt et al., 2010). The concentration of MAp44 in serum is $1.7 \mu \mathrm{g} / \mathrm{ml}$ (Degn et al., 2010), and since it contain all the domains necessary for MBL or ficolin interaction, but lacks the SP domain, MAp44 can inhibit the lectin pathway by competition with the MASPs (Degn et al., 2009; Skjoedt et al., 2012). A regulatory role of MAp44 was seen in a myocardial ischemia/reperfusion mouse model, where supplemented high concentrations of rMAp44 protects against pathophysical outcome of myocardial ischemia/reperfusion, and in an occlusive thrombogenesis mouse model, where MAp44 inhibits thrombogenesis (Pavlov et al., 2012).

\section{Structural studies of the lectin pathway}

\subsection{The architecture of the pattern recognition molecules}

A trimer of $\mathrm{MBL}$ is the basic building block that is organized in oligomers ranging from dimers to octamers. Studies with electron microscopy and atomic force microscopy (Jensenius et al., 2009; Lu et al., 1990) suggested that these oligomers are assembled through the Cys-rich $\mathrm{N}$-terminal region from which the collagen 
stems and the CRDs protrude to form near-planar oligomers or more three dimensional bouquets, which is also the case for ficolins (Gout et al., 2011; Lacroix et al., 2009). Small angle X-ray studies of dimers, trimers and tetramers of rat MBL revealed a near planar fan-like arrangement with unkinked collagen stems and with an approximate angle of $45^{\circ}$ between the collagen stem and the neck region (Miller et al., 2012). Crystallographic studies of the MBL CRD showed how the C-type lectin domain binds terminal mannose residues in a calcium dependent manner (Weis et al., 1991, 1992). The calcium ion is coordinated by the horizontal $3^{\prime}-$ and $4^{\prime}-\mathrm{OH}$ of the mannose together with side chain and main atoms from two asparagines and two aspartates of the CRD, and these residues simultaneously form hydrogen bonds with the mannose. The structures of trimeric CRD (Sheriff et al., 1994; Weis and Drickamer, 1994) showed that the neck region trimerizes through a parallel coil-coil packing leading to exposure of the three glycan binding sites at the distant end of the CRD trimer, where they are well suited for recognition of large planar like glycans such as an LPS layer. Structures of the glycan binding FBG domain of all three ficolins (Garlatti et al., 2007a, 2007b; Tanio et al., 2007) revealed a conserved structure with the FBG organized in three lobes. In contrast to MBL, the ficolin FBGs form stable trimers without possessing a neck region. Furthermore, $\mathrm{Ca}^{2+}$ ions are not coordinating bound carbohydrate as in MBL, but instead order regions involved in glycan binding. All ficolins possess the S1 binding site for carbohydrate residues located on the periphery of the trimer (Garlatti et al., 2007b; Gingras et al., 2011), but Lficolin contains three additional carbohydrate binding sites. These sites form a continuous recognition surface that can interact with acetylated and neutral carbohydrates in an extended polysaccharide (Garlatti et al., 2007a). Despite the very different structures of the protomers and glycan specificity, the trimers of ficolin and MBL are functionally similar by presenting exposed glycan binding site at the far end of the domain relative to the collagen/neck region at the periphery of the trimer and with roughly 50 Å between the primary carbohydrate binding sites (Tanio et al., 2007).

\subsection{Atomic structures of the MASPs, MAp19 and MAp44}

Crystallographic studies of the CUB1-EGF-CUB2 fragment of rat MASP-2 revealed how MASP-2 dimerizes in a head-to-tail manner around a two-fold axis relating the CUB1 and the EGF domains on opposite monomers, whereas CUB2 is not involved in the dimerization (Feinberg et al., 2003). This study did not identify the crucial $\mathrm{Ca}^{2+}$ sites in the CUB domains, but only in the EGF domain. The CUB1 calcium site was subsequently identified in the structure of MAp19. Mutation of calcium coordinating residues or nearby residues in CUB1 was show to inhibit MAp19 interaction with L-ficolin and MBL (Gregory et al., 2004). The CUB2 calcium site was described in the structure of the MASP-1 CUB1-EGF-CUB2 fragment, where all three calcium sites (EGF, CUB1 and CUB2) were occupied. The dimer arrangement in MASP-1 is quite similar to that of MASP-2 suggesting a highly conserved dimerization mode for the MASP proteases. In both CUB domains two aspartates, one glutamate side chain and a main carbonyl coordinate the calcium, whereas additional coordination is done by other polar side chains and water molecules (Teillet et al., 2008). The result of $\mathrm{Ca}^{2+}$ binding to a MASP CUB domain is the organization of three acidic side chains around the ion, and mutation in these acidic residues or nearby residues decreased the interaction of MASP-3 with MBL, L-ficolin and H-ficolin (Teillet et al., 2008).

Structures of the catalytic active SP domain and the CCP domains from MASP-1 and MASP-2 have also been determined. A comparison of the structures of active (i.e. cleaved) MASP-2 CCP2-SP and zymogen (non-cleaved) MASP-2 CCP1-CCP2-SP showed that the SP domain undergoes a significant internal conformational change upon its proteolytic activation and minor rotation relative to the CCP2 domain. In the MASP-2 zymogen enzyme, the oxyanion hole for recognizing the carbonyl group of the scissile bond is absent and the $\mathrm{S} 1$ pocket accommodating the arginine side chain from the $\mathrm{P} 1$ residue of the substrate is closed by a MASP-2 arginine (Gal et al., 2005; Harmat et al., 2004). The structure of the CCP1CCP2-SP fragment from MASP-1 in its active conformation revealed a quite accessible substrate binding groove explaining its relaxed specificity relative to MASP-2 (Dobo et al., 2009). The CCP1-CCP2 domains in both MASP-1 and MASP-2 form a rather rigid unit giving the overall appearance of a mace to the CCP1-CCP2-SP moiety of the two MASPs.

The structure of MAp44 showed how the CCP1 domain is interacting with the CUB2 domain in MASP-1 (Skjoedt et al., 2012), and superposition of the overlapping structures of MAp44, MASP1 CCP1-CCP2-SP and MASP-1 CUB1-EGF-CUB2 allowed modeling of an intact dimeric MASP protease. This is flat, highly elongated and with a maximum dimension of $330 \AA$ A between the extremes of the two SP domains (Skjoedt et al., 2012). The domain interface between CUB2 and CCP1 is formed by a phenylalanine from each domain surrounded by two putative salt bridges extending across the domain interface. All participating residues are highly conserved in MASP-1 and MASP-2 although one phenylalanine is a leucine in the latter. The resolution of the MAp44 structure is only $4.2 \AA$, but the structure is likely to be trustworthy based on comparison with the structures of MASP- 1 fragments containing the same domains.

\subsection{The calcium dependent interaction of MBL with a CUB domain}

A crucial step in understanding the structural aspects of the lectin pathway is to describe how the MASP CUB domains recognize the collagen stems in the pattern recognition molecules. Functional studies had indicated that a very highly conserved lysine corresponding to Lys75 (pre-numbering used for MBL and other proteins in the following) in human MBL was essential for interaction of the collagen triple helix in MBL (Teillet et al., 2007) and ficolins (Girija et al., 2007; Lacroix et al., 2009; Teillet et al., 2007) with the CUB calcium sites in the MASP proteases. This was finally confirmed with the structure of the complex between the MASP1 CUB2 domain and a trimeric peptide containing the OGKLGP (O meaning hydroxyproline) binding motif of MBL (Gingras et al., 2011). The lysine side chain of the leading strand interacts with two of the acidic side chains and a serine organized around the calcium ion as already observed for ligand interaction with a calcium binding CUB domain of the cubilin receptor (Andersen et al., 2010). Based on interactions between MASP-1 and a conserved groove in the collagen strand it was concluded that the observed orientation of the collagen strand relative to the CUB domain is of physiological relevance and conserved in the interaction of CL-K1 and ficolins with MASPs (Gingras et al., 2011). By combining the MASP1 CUB2:collagen structure with most of the partially overlapping structures of MBL and MASPs mentioned, we have constructed an overall model for a dimeric MASP protease bound to a tetrameric MBL molecule (Fig. 2C and D), see supplementary text for details on the modeling.

\subsection{Cis- or trans activation of MASPs}

A pertinent question is how the MASPs in complex with MBL, CL-K1 or ficolins are activated. A trimer or tetramer of MBL would most likely only bind a single MASP dimer. For cis-activation within the same MASP dimer, the two serine protease domain 

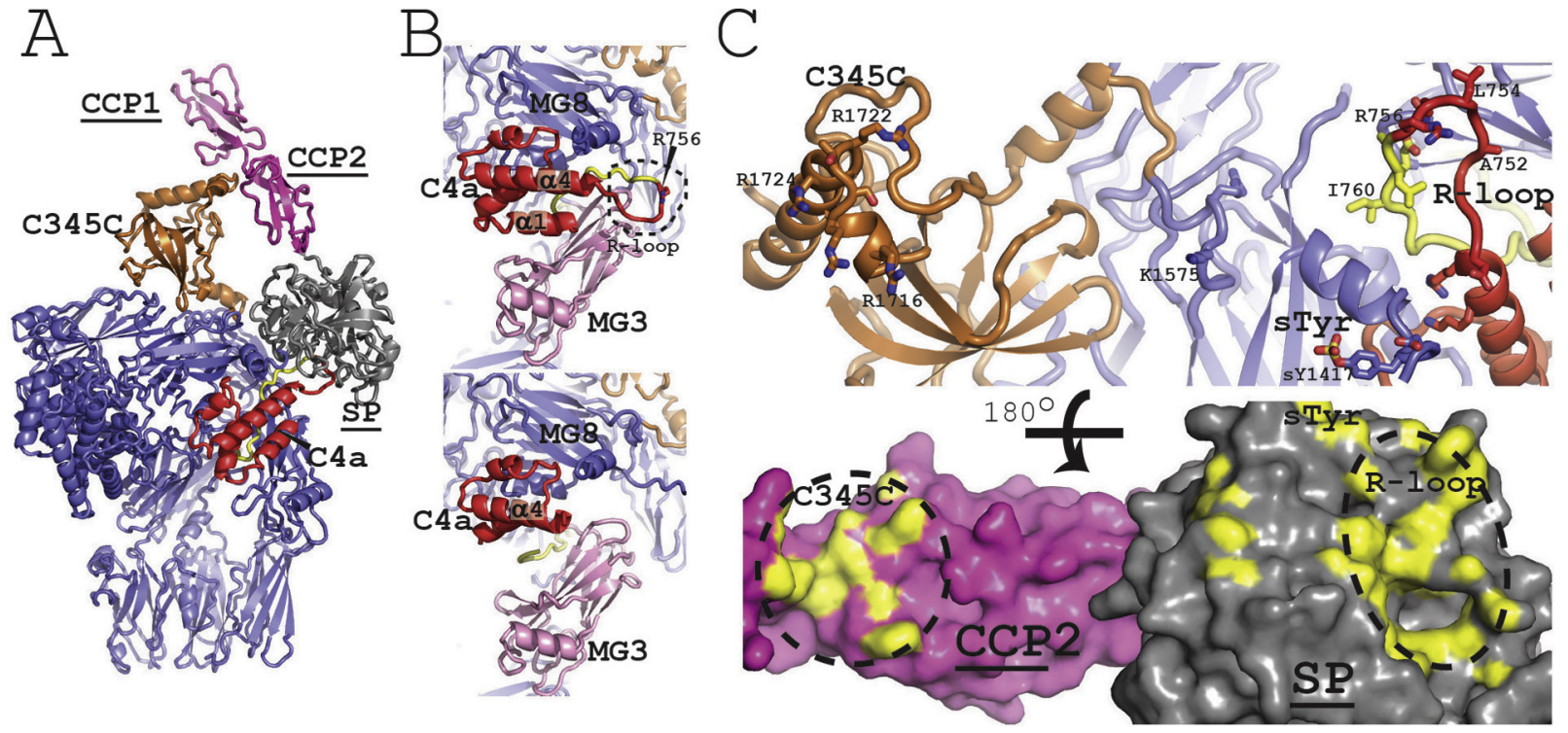

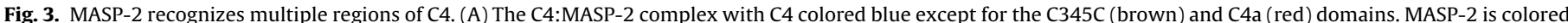

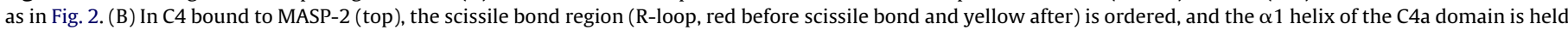

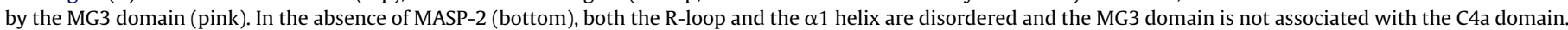

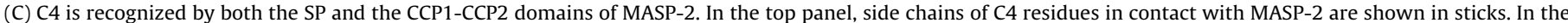

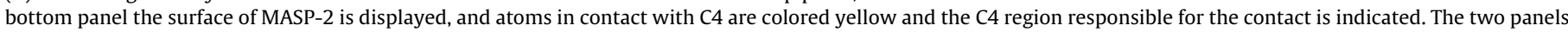
are related by a $180^{\circ}$ rotation around a horizontal axis.

would have to come into contact within the MBL tetramer to auto-activate (Chen and Wallis, 2004). Such close approach of the two SP domains would require a major structural rearrangement within the CUB2 or the CCP1 domains compared to our MBL:MASP model, and there is no structural evidence for such flexibility. Furthermore, such cis-activation would not explain the importance of MASP-1 on MASP-2s activity (Fig. 1), as heterodimerization (i.e. a MASP-1-MASP-2 dimer) has never been documented. For larger MBL oligomers, two MASP dimers (e.g. a MASP-1 and a MASP-2 dimer) could possibly be bound to one MBL molecule. MASP- 1 could then activate zymogen MASP-2, and the lectin pathway could commence. The existence of such complexes has been observed (Degn et al., 2012). Such cis-activation could potentially be combined with the trans-activation model discussed below.

The model in the present report favor trans-activation between MASP dimers bound to adjacent glycan bound MBL molecules, which explains the importance of MASP-1 on the lectin pathway activity (Degn et al., 2012; Heja et al., 2012). Zymogen MASP-1 on one MBL molecule could transactivate zymogen MASP-1 on another MBL molecule, which could then activate other MBL-bound MASP-1 and MASP-2 (Fig. 1). Trans-activation is compatible with our molecular model of the MBL:MASP complexes, and in particular with our orientation of the MBL collagen stem relative to the CUB domains (see supplementary text for discussion of this).

\section{The structural basis for cleavage of C4 by MASP-2}

A major step forward toward understanding in structural details how complement activation occurs through the lectin pathway was recently made with our structure of the complex between human complement $\mathrm{C} 4$ and a CCP1-CCP2-SP fragment of MASP-2 (Fig. $3 \mathrm{~A}$ and $\mathrm{B}$ ) where the catalytic triad serine was substituted with an alanine (Kidmose et al., 2012).

\subsection{MASP-2 interacts with C4 at three sites}

Despite a limited resolution of 3.7 A this structure probably represents quite accurately a Michaelis complex. The scissile bond region was found to be ordered with the P1 residue Arg756 from C4 inserted in the S1 site of MASP-2 and the scissile bond carbonyl apparently placed in the oxyanion hole (Fig. 3C). The C4:MASP2 structure also revealed a strongly positively charged exosite on the SP domain of MASP-2 interacting with the heavily negatively charged sulfotyrosine region in the substrate, and a similar SP exosite was recently demonstrated to be present in $\mathrm{C} 1 \mathrm{~s}$ from the classical pathway as well (Duncan et al., 2012). The existence of another exosite in both C1s and MASP-2 involving the CCP domains was suggested by biochemical studies (Ambrus et al., 2003; Duncan et al., 2012; Rossi et al., 2005). The structure of the C4:MASP-2 complex revealed that the $\mathrm{CCP}$ exosite is located between the two $\mathrm{CCP}$ domains with the largest contribution from CCP2 (Fig. 3C). From the substrate a very positively charged patch on the C-terminal C $345 \mathrm{C}$ domain is inserted into a negatively charged valley formed between the CCP domains, and mutations in MASP-2 residues involved in interactions at the CCP exosite caused a reduced efficiency in C4 cleavage (Kidmose et al., 2012). The existence of this exosite in C1s as well was further supported by the ability of the recombinant C345C domain to inhibit C4 cleavage by $\mathrm{C} 1 \mathrm{~s}$ and a similar electrostatic potential at the putative CCP exosite in $\mathrm{C} 1 \mathrm{~s}$ similar to that observed in MASP-2 (Kidmose et al., 2012). Comparison with the structures of unbound C4 and MASP-2 revealed how formation of the Michaelis complex induces substantial rearrangements in both enzyme and substrate (Fig. 3B). In MASP-2, the SP domain rotates by $25^{\circ}$, while domain movements in C4 apparently help to stabilize the conformation of scissile bond region thereby promoting its interaction with MASP-2 (Kidmose et al., 2012).

\subsection{A model for C4 cleavage by glycan bound MBL:MASP-2}

To develop an MBL:MASP-2:C4 model, the CCP1 domain of the C4:MASP-2 complex (Kidmose et al., 2012) is superimposed onto 

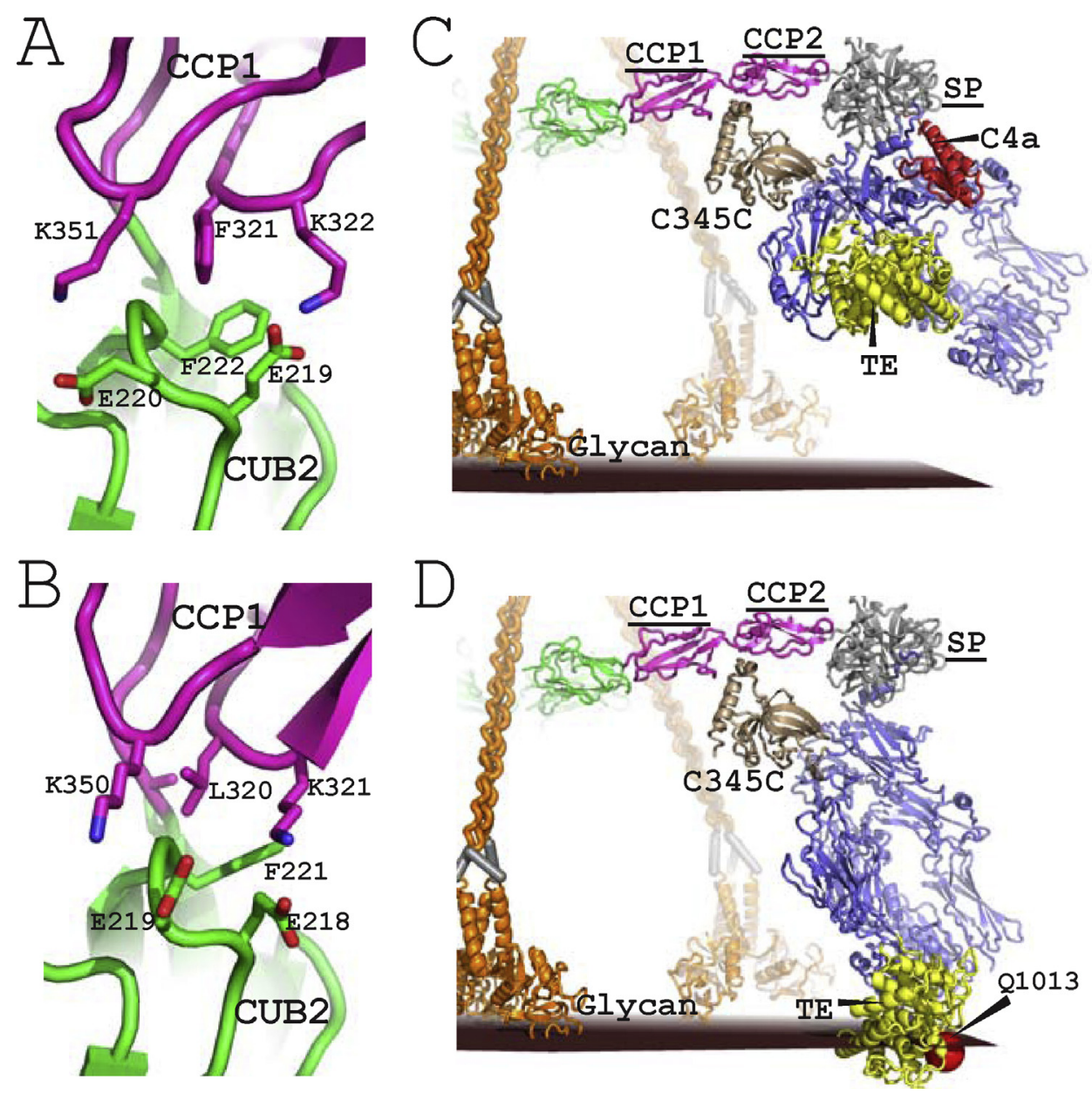

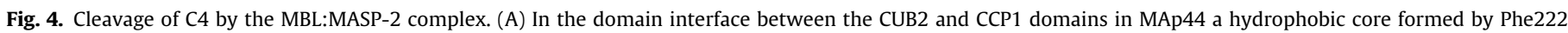

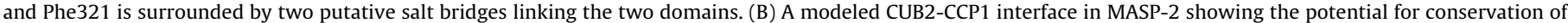

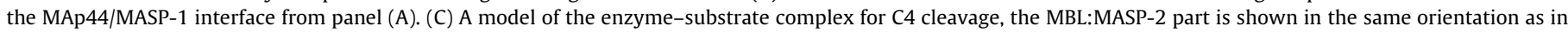

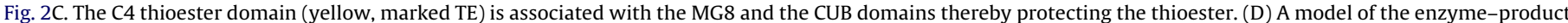

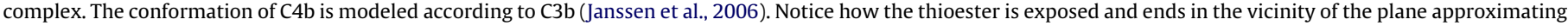
the glycan plane in an optimal position to mediate activator opsonization. In panels (C) and (D) MASP-2 legends are underlined.

the CCP1-CCP2 domains in our general MBL:MASP model (Fig. 2C and $\mathrm{D})$. The underlying assumption is that the CUB2-CCP1 interface is structurally conserved in MASP-2 and MASP-1, but this is reasonable as both have the $\mathrm{C} 4 \mathrm{~b} 2$ proconvertase as substrate and supported by the conservation of the domain interface (Fig. 4A and B). An interesting outcome of this enzyme-substrate model appears if the plane approximating the glycan binding sites of MBL is taken into account. It turns out that C4 might be approaching MBL:MASP2 in an orientation with its long axis inclined by roughly $30^{\circ}$ relative to the glycan plane (Fig. 4C). This is appealing as the model predicts the steric hindrance between the incoming C4 and the glycan layer to be minimal. The structure of C4b is unknown, but if it is modeled according to that of C3b (Janssen et al., 2006) and in the product complex the $\mathrm{C} 345 \mathrm{C}$ domain of $\mathrm{C} 4 \mathrm{~b}$ transiently maintains its interaction with the MASP-2 CCP domains as previously suggested (Wallis et al., 2007), another very important expectation is fulfilled. The C4b thioester is directed toward the glycan layer and ends up more or less at the same "height" as the glycan binding sites of MBL (Fig. 4D).

\section{Conclusion and outlook}

Activation of the complement system is a strong inflammatory response toward infections or toward damaged cells or tissues. On one hand this leads to protection but on the other hand it may have fatal outcome if the inflammation generating processes are not properly controlled by host complement inhibitors. It is thus important to unravel the mechanisms leading to complement activation. In the present report we suggest a model for the activation via MBL/MASP complexes. Although a complete detailed structure based description of the lectin pathway is very difficult to achieve especially due to the complexity of the glycan surface being recognized, a quite complete structural framework is now emerging. In particular, the recent crystal structures have allowed the assembly of overall approximate atomic models compatible with well-established functional properties of the lectin pathway and its endpoint, the assembly of the $\mathrm{C} 3$ convertase. Apart from continued studies on the structural elements the biological roles of some of the MASPs are maybe still to be discovered and the results of deficiencies of lectin pathway components in diseases needs to be defined better.

\section{Acknowledgements}

We are grateful to S. Degn, R.T. Kidmose and C. Gaboriaud for discussions. Our work was supported by the Lundbeck Foundation. GRA was further supported through a Hallas-Møller stipend from the Novo-Nordisk Foundation and the LUNA Nanomedicine Center. 


\section{Appendix A. Supplementary data}

Supplementary data associated with this article can be found, in the online version, at http://dx.doi.org/10.1016/j.molimm. 2013.05.007.

\section{References}

Ali, Y.M., Lynch, N.J., Haleem, K.S., Fujita, T., Endo, Y., Hansen, S., Holmskov, U., Takahashi, K., Stahl, G.L., Dudler, T., Girija, U.V., Wallis, R., Kadioglu, A., Stover, C.M., Andrew, P.W., Schwaeble, W.J., 2012. The lectin pathway of complement activation is a critical component of the innate immune response to pneumococcal infection. PLoS Pathogens 8, e1002793.

Ambrus, G., Gal, P., Kojima, M., Szilagyi, K., Balczer, J., Antal, J., Graf, L., Laich, A., Moffatt, B.E., Schwaeble, W., Sim, R.B., Zavodszky, P., 2003. Natural substrates and inhibitors of mannan-binding lectin-associated serine protease- 1 and -2 : a study on recombinant catalytic fragments. Journal of Immunology 170, 1374-1382.

Andersen, C.B., Madsen, M., Storm, T., Moestrup, S.K., Andersen, G.R., 2010. Structural basis for receptor recognition of vitamin-B(12)-intrinsic factor complexes. Nature 464, 445-448.

Aoyagi, Y., Adderson, E.E., Min, J.G., Matsushita, M., Fujita, T., Takahashi, S., Okuwaki, Y., Bohnsack, J.F., 2005. Role of L-ficolin/mannose-binding lectin-associated serine protease complexes in the opsonophagocytosis of type III group B streptococci. Journal of Immunology 174, 418-425.

Aoyagi, Y., Adderson, E.E., Rubens, C.E., Bohnsack, J.F., Min, J.G., Matsushita, M., Fujita, T., Okuwaki, Y., Takahashi, S., 2008. L-ficolin/mannose-binding lectin-associated serine protease complexes bind to group $\mathrm{B}$ streptococci primarily through $\mathrm{N}$ acetylneuraminic acid of capsular polysaccharide and activate the complement pathway. Infection and Immunity 76, 179-188.

Carroll, M.V., Lack, N., Sim, E., Krarup, A., Sim, R.B., 2009. Multiple routes of complement activation by Mycobacterium bovis BCG. Molecular Immunology 46, 3367-3378.

Cestari Idos, S., Krarup, A., Sim, R.B., Inal, J.M., Ramirez, M.I., 2009. Role of early lectin pathway activation in the complement-mediated killing of Trypanosoma cruzi. Molecular Immunology 47, 426-437.

Chen, C.B., Wallis, R., 2004. Two mechanisms for mannose-binding protein modulation of the activity of its associated serine proteases. Journal of Biological Chemistry 279, 26058-26065.

Dahl, M.R., Thiel, S., Matsushita, M., Fujita, T., Willis, A.C., Christensen, T., VorupJensen, T., Jensenius, J.C., 2001. MASP-3 and its association with distinct complexes of the mannan-binding lectin complement activation pathway. Immunity $15,127-135$.

Degn, S.E., Hansen, A.G., Steffensen, R., Jacobsen, C., Jensenius, J.C., Thiel, S., 2009. MAp44, a human protein associated with pattern recognition molecules of the complement system and regulating the lectin pathway of complement activation. Journal of Immunology 183, 7371-7378.

Degn, S.E., Jensen, L., Gal, P., Dobo, J., Holmvad, S.H., Jensenius, J.C., Thiel, S., 2010. Biological variations of MASP-3 and MAp44, two splice products of the MASP1 gene involved in regulation of the complement system. Journal of Immunological Methods 361, 37-50.

Degn, S.E., Jensen, L., Hansen, A.G., Duman, D., Tekin, M., Jensenius, J.C., Thiel, S., 2012. Mannan-binding lectin-associated serine protease (MASP)-1 is crucial for lectin pathway activation in human serum, whereas neither MASP-1 nor MASP-3 is required for alternative pathway function. Journal of Immunology 189, 3957-3969.

Degn, S.E., Thiel, S., Nielsen, O., Hansen, A.G., Steffensen, R., Jensenius, J.C., 2011. MAp19, the alternative splice product of the MASP2 gene. Journal of Immunological Methods 373, 89-101.

Dobo, J., Harmat, V., Beinrohr, L., Sebestyen, E., Zavodszky, P., Gal, P., 2009. MASP-1, a promiscuous complement protease: structure of its catalytic region reveals the basis of its broad specificity. Journal of Immunology 183, 1207-1214

Dobo, J., Major, B., Kekesi, K.A., Szabo, I., Megyeri, M., Hajela, K., Juhasz, G., Zavodszky, P., Gal, P., 2011. Cleavage of kininogen and subsequent bradykinin release by the complement component: mannose-binding lectin-associated serine protease (MASP)-1. PLoS One 6, e20036.

Duncan, R.C., Bergstrom, F., Coetzer, T.H., Blom, A.M., Wijeyewickrema, L.C., Pike, R.N., 2012. Multiple domains of MASP-2, an initiating complement protease, are required for interaction with its substrate C4. Molecular Immunology 49, 593-600.

Duus, K., Thielens, N.M., Lacroix, M., Tacnet, P., Frachet, P., Holmskov, U., Houen, G., 2010. CD91 interacts with mannan-binding lectin (MBL) through the MBLassociated serine protease-binding site. FEBS Journal 277, 4956-4964.

Evans-Osses, I., Ansa-Addo, E.A., Inal, J.M., Ramirez, M.I., 2010. Involvement of lectin pathway activation in the complement killing of Giardia intestinalis. Biochemical and Biophysical Research Communications 395, 382-386.

Feinberg, H., Uitdehaag, J.C., Davies, J.M., Wallis, R., Drickamer, K., Weis, W.I., 2003. Crystal structure of the CUB1-EGF-CUB2 region of mannose-binding protein associated serine protease-2. EMBO Journal 22, 2348-2359.

Fuchs, A., Pinto, A.K., Schwaeble, W.J., Diamond, M.S., 2011. The lectin pathway of complement activation contributes to protection from West Nile virus infection. Virology 412, 101-109.

Gal, P., Harmat, V., Kocsis, A., Bian, T., Barna, L., Ambrus, G., Vegh, B., Balczer, J., Sim, R.B., Naray-Szabo, G., Zavodszky, P., 2005. A true autoactivating enzyme.
Structural insight into mannose-binding lectin-associated serine protease-2 activations. Journal of Biological Chemistry 280, 33435-33444.

Garlatti, V., Belloy, N., Martin, L., Lacroix, M., Matsushita, M., Endo, Y., Fujita T., Fontecilla-Camps, J.C., Arlaud, G.J., Thielens, N.M., Gaboriaud, C., 2007a. Structural insights into the innate immune recognition specificities of L- and H-ficolins. EMBO Journal 26, 623-633.

Garlatti, V., Martin, L., Gout, E., Reiser, J.B., Fujita, T., Arlaud, G.J., Thielens, N.M., Gaboriaud, C., 2007b. Structural basis for innate immune sensing by M-ficolin and its control by a pH-dependent conformational switch. Journal of Biological Chemistry 282, 35814-35820.

Ghiran, I., Barbashov, S.F., Klickstein, L.B., Tas, S.W., Jensenius, J.C., Nicholson-Weller, A., 2000. Complement receptor $1 / C D 35$ is a receptor for mannan-binding lectin. Journal of Experimental Medicine 192, 1797-1808.

Gingras, A.R., Girija, U.V., Keeble, A.H., Panchal, R., Mitchell, D.A., Moody, P.C., Wallis, R., 2011. Structural basis of mannan-binding lectin recognition by its associated serine protease MASP-1: implications for complement activation. Structure 19 , 1635-1643.

Girija, U.V., Dodds, A.W., Roscher, S., Reid, K.B., Wallis, R., 2007. Localization and characterization of the mannose-binding lectin (MBL)-associated-serine protease-2 binding site in rat ficolin-A: equivalent binding sites within the collagenous domains of MBLs and ficolins. Journal of Immunology 179, 455-462.

Gout, E., Garlatti, V., Smith, D.F., Lacroix, M., Dumestre-Pérard, C., Lunardi, T., Martin, L., Cesbron, J.-Y., Arlaud, G.J., Gaboriaud, C., Thielens, N.M., 2010. Carbohydrate recognition properties of human ficolins: glycan array screening reveals the sialic acid binding specificity of M-ficolin. Journal of Biological Chemistry 285 6612-6622

Gout, E., Moriscot, C., Doni, A., Dumestre-Perard, C., Lacroix, M., Perard, J., Schoehn, G., Mantovani, A., Arlaud, G.J., Thielens, N.M., 2011. M-ficolin interacts with the long pentraxin PTX3: a novel case of cross-talk between soluble pattern-recognition molecules. Journal of Immunology 186, 5815-5822.

Gregory, L.A., Thielens, N.M., Matsushita, M., Sorensen, R., Arlaud, G.J., FontecillaCamps, J.C., Gaboriaud, C., 2004. The X-ray structure of human mannan-binding lectin-associated protein 19 (MAp19) and its interaction site with mannanbinding lectin and L-ficolin. Journal of Biological Chemistry 279, 29391-29397.

Hansen, S., Selman, L., Palaniyar, N., Ziegler, K., Brandt, J., Kliem, A., Jonasson, M. Skjoedt, M.-O., Nielsen, O., Hartshorn, K., Jørgensen, T.J.D., Skjødt, K., Holmskov, U., 2010. Collectin 11 (CL-11, CL-K1) is a MASP-1/3-associated plasma collectin with microbial-binding activity. Journal of Immunology 185, 6096-6104.

Harmat, V., Gal, P., Kardos, J., Szilagyi, K., Ambrus, G., Vegh, B., Naray-Szabo, G.,Zavodszky, P., 2004. The structure of MBL-associated serine protease-2 reveals that identical substrate specificities of C1s and MASP-2 are realized through different sets of enzyme-substrate interactions. Journal of Molecular Biology 342, 1533-1546.

Harumiya, S., Takeda, K., Sugiura, T., Fukumoto, Y., Tachikawa, H., Miyazono, K., Fujimoto, D., Ichijo, H., 1996. Characterization of ficolins as novel elastin-binding proteins and molecular cloning of human ficolin-1. Journal of Biochemistry 120, 745-751.

Heja, D., Kocsis, A., Dobo, J., Szilagyi, K., Szasz, R., Zavodszky, P., Pal, G., Gal, P., 2012. Revised mechanism of complement lectin-pathway activation revealing the role of serine protease MASP-1 as the exclusive activator of MASP-2. Proceedings of the National Academy of Sciences of the United States of America 109, 10498-10503.

Honore, C., Hummelshoj, T., Hansen, B.E., Madsen, H.O., Eggleton, P., Garred, P., 2007. The innate immune component ficolin 3 (Hakata antigen) mediates the clearance of late apoptotic cells. Arthritis and Rheumatism 56, 1598-1607.

Honore, C., Rorvig, S., Hummelshoj, T., Skjoedt, M.O., Borregaard, N., Garred, P., 2010. Tethering of Ficolin-1 to cell surfaces through recognition of sialic acid by the fibrinogen-like domain. Journal of Leukocyte Biology 88, 145-158.

Inaba, S., Okochi, K., Yae, Y., Niklasson, F., de Verder, C.H., 1990. Serological studies of an SLE-associated antigen-antibody system discovered as a precipitation reaction in agarose gel: the HAKATA antigen-antibody system. Fukuoka Igaku Zasshi 81, 284-291.

Iwaki, D., Kanno, K., Takahashi, M., Endo, Y., Lynch, N.J., Schwaeble, W.J., Matsushita, M., Okabe, M., Fujita, T., 2006. Small mannose-binding lectin-associated protein plays a regulatory role in the lectin complement pathway. Journal of Immunology $177,8626-8632$.

Iwaki, D., Kanno, K., Takahashi, M., Endo, Y., Matsushita, M., Fujita, T., 2011. The role of mannose-binding lectin-associated serine protease- 3 in activation of the alternative complement pathway. Journal of Immunology 187, 3751-3758.

Jacquet, M., Lacroix, M., Ancelet, S., Gout, E., Gaboriaud, C., Thielens, N.M., Rossi, V., 2013. Deciphering complement receptor type 1 interactions with recognition proteins of the lectin complement pathway. Journal of Immunology 190, 3721-3731.

Janssen, B.J., Christodoulidou, A., McCarthy, A., Lambris, J.D., Gros, P., 2006. Structure of $\mathrm{C} 3 \mathrm{~b}$ reveals conformational changes that underlie complement activity. Nature 444, 213-216.

Jensenius, H., Klein, D.C., van Hecke, M., Oosterkamp, T.H., Schmidt, T., Jensenius, J.C. 2009. Mannan-binding lectin: structure, oligomerization, and flexibility studied by atomic force microscopy. Journal of Molecular Biology 391, 246-259.

Kang, I., Kim, J.I., Chang, S.G., Lee, S.J., Choi, S.L., Ha, J., Kim, S.S., 1999. Mannan-binding lectin (MBL)-associated plasma protein present in human urine inhibits calcium oxalate crystal growth. FEBS Letters 462, 89-93.

Keshi, H., Sakamoto, T., Kawai, T., Ohtani, K., Katoh, T., Jang, S.J., Motomura, W. Yoshizaki, T., Fukuda, M., Koyama, S., Fukuzawa, J., Fukuoh, A., Yoshida, I., Suzuki, Y., Wakamiya, N., 2006. Identification and characterization of a novel human collectin CL-K1. Microbiology and Immunology 50, 1001-1013. 
Kidmose, R.T., Laursen, N.S., Dobo, J., Kjaer, T.R., Sirotkina, S., Yatime, L., SottrupJensen, L., Thiel, S., Gal, P., Andersen, G.R., 2012. Structural basis for activation of the complement system by component C4 cleavage. Proceedings of the National Academy of Sciences of the United States of America 109, 15425-15430.

Kjaer, T.R., Hansen, A.G., Sorensen, U.B., Holm, A.T., Sorensen, G.L., Jensenius, J.C., Thiel, S., 2013. M-ficolin binds selectively to the capsular polysaccharides of Streptococcus pneumoniae serotypes $19 \mathrm{~B}$ and $19 \mathrm{C}$ and of a Streptococcus mitis strain. Infection and Immunity 81, 452-459.

Kjaer, T.R., Hansen, A.G., Sorensen, U.B., Nielsen, O., Thiel, S., Jensenius, J.C., 2011. Investigations on the pattern recognition molecule M-ficolin: quantitative aspects of bacterial binding and leukocyte association. Journal of Leukocyte Biology 90, 425-437.

Krarup, A., Mitchell, D.A., Sim, R.B., 2008. Recognition of acetylated oligosaccharides by human L-ficolin. Immunology Letters 118, 152-156.

Krarup, A., Sorensen, U.B., Matsushita, M., Jensenius, J.C., Thiel, S., 2005. Effect of capsulation of opportunistic pathogenic bacteria on binding of the pattern recognition molecules mannan-binding lectin, L-ficolin, and $\mathrm{H}$-ficolin. Infection and Immunity 73, 1052-1060.

Krarup, A., Thiel, S., Hansen, A., Fujita, T., Jensenius, J.C., 2004. L-ficolin is a pattern recognition molecule specific for acetyl groups. Journal of Biological Chemistry $279,47513-47519$

Kuraya, M., Ming, Z., Liu, X., Matsushita, M., Fujita, T., 2005. Specific binding of L-ficolin and H-ficolin to apoptotic cells leads to complement activation. Immunobiology 209, 689-697.

Lacroix, M., Dumestre-Perard, C., Schoehn, G., Houen, G., Cesbron, J.Y., Arlaud, G.J., Thielens, N.M., 2009. Residue Lys57 in the collagen-like region of human L-ficolin and its counterpart Lys47 in H-ficolin play a key role in the interaction with the mannan-binding lectin-associated serine proteases and the collectin receptor calreticulin. Journal of Immunology 182, 456-465.

Le, Y., Lee, S.H., Kon, O.L., Lu, J., 1998. Human L-ficolin: plasma levels, sugar specificity, and assignment of its lectin activity to the fibrinogen-like (FBG) domain. FEBS Letters 425, 367-370.

Liu, J., Ali, M.A., Shi, Y., Zhao, Y., Luo, F., Yu, J., Xiang, T., Tang, J., Li, D., Hu, Q., Ho, W., Zhang, X., 2009. Specifically binding of L-ficolin to N-glycans of HCV envelope glycoproteins E1 and E2 leads to complement activation. Cellular \& Molecular Immunology 6, 235-244.

Liu, Y., Endo, Y., Iwaki, D., Nakata, M., Matsushita, M., Wada, I., Inoue, K., Munakata, M. Fujita, T., 2005. Human M-ficolin is a secretory protein that activates the lectin complement pathway. Journal of Immunology 175, 3150-3156.

Lu, J., Tay, P.N., Kon, O.L., Reid, K.B., 1996. Human ficolin: cDNA cloning, demonstration of peripheral blood leucocytes as the major site of synthesis and assignment of the gene to chromosome 9. Biochemical Journal 313 (Pt 2), 473-478.

Lu, J.H., Thiel, S., Wiedemann, H., Timpl, R., Reid, K.B., 1990. Binding of the pentamer/hexamer forms of mannan-binding protein to zymosan activates the proenzyme $\mathrm{C} 1 \mathrm{r} 2 \mathrm{C} 1 \mathrm{~s} 2$ complex, of the classical pathway of complement, without involvement of C1q. Journal of Immunology 144, 2287-2294.

Lynch, N.J., Roscher, S., Hartung, T., Morath, S., Matsushita, M., Maennel, D.N., Kuraya, M., Fujita, T., Schwaeble, W.J., 2004. L-ficolin specifically binds to lipoteichoic acid, a cell wall constituent of Gram-positive bacteria, and activates the lectin pathway of complement. Journal of Immunology 172, 1198-1202.

Ma, Y.J., Doni, A., Hummelshoj, T., Honore, C., Bastone, A., Mantovani, A., Thielens, N.M., Garred, P., 2009. Synergy between ficolin-2 and pentraxin 3 boosts innate immune recognition and complement deposition. Journal of Biological Chemistry 284, 28263-28275.

Ma, Y.J., Skjoedt, M.O., Garred, P., 2013. Collectin-11/MASP complex formation triggers activation of the lectin complement pathway - the fifth lectin pathway initiation complex. Journal of Innate Immunity 5, 242-250.

Matsushita, M., Endo, Y., Taira, S., Sato, Y., Fujita, T., Ichikawa, N., Nakata, M. Mizuochi, T., 1996. A novel human serum lectin with collagen- and fibrinogenlike domains that functions as an opsonin. Journal of Biological Chemistry 271 2448-2454.

Matsushita, M., Fujita, T., 1992. Activation of the classical complement pathway by mannose-binding protein in association with a novel C1s-like serine protease. Journal of Experimental Medicine 176, 1497-1502.

Matsushita, M., Fujita, T., 1995. Cleavage of the third component of complement (C3) by mannose-binding protein-associated serine protease (MASP) with subsequent complement activation. Immunobiology 194, 443-448.

Megyeri, M., Harmat, V., Major, B., Vegh, A., Balczer, J., Heja, D., Szilagyi, K., Datz, D., Pal, G., Zavodszky, P., Gal, P., Dobo, J., 2013. Quantitative characterization of the activation steps of mannan-binding lectin (MBL)-associated serine proteases (MASPs) points to the central role of MASP-1 in the initiation of the complement lectin pathway. Journal of Biological Chemistry 288, 8922-8934.

Miller, A., Phillips, A., Gor, J., Wallis, R., Perkins, S.J., 2012. Near-planar solution structures of mannose-binding lectin oligomers provide insight on activation of lectin pathway of complement. Journal of Biological Chemistry 287, 3930-3945.

Moller-Kristensen, M., Thiel, S., Jensenius, J., 2009. Mannan-binding lectin polymorphisms and infectious diseases. In: Vasta, G., Ahmed, H. (Eds.), Animal Lectins: A Functional View. CRC Press, Boca Raton, FL, pp. 303-332

Moller-Kristensen, M., Thiel, S., Sjoholm, A., Matsushita, M., Jensenius, J.C., 2007. Cooperation between MASP-1 and MASP-2 in the generation of C3 convertase through the MBL pathway. International Immunology 19, 141-149.

Moreno-Amaral, A.N., Gout, E., Danella-Polli, C., Tabarin, F., Lesavre, P., Pereira-daSilva, G., Thielens, N.M., Halbwachs-Mecarelli, L., 2012. M-ficolin and leukosialin (CD43): new partners in neutrophil adhesion. Journal of Leukocyte Biology 91 469-474.
Munthe-Fog, L., Hummelshoj, T., Honore, C., Madsen, H.O., Permin, H., Garred, P., 2009. Immunodeficiency associated with FCN3 mutation and ficolin-3 deficiency. New England Journal of Medicine 360, 2637-2644.

Nauta, A.J., Raaschou-Jensen, N., Roos, A., Daha, M.R., Madsen, H.O., Borrias-Essers, M.C., Ryder, L.P., Koch, C., Garred, P., 2003. Mannose-binding lectin engagement with late apoptotic and necrotic cells. European Journal of Immunology 33, 2853-2863.

Nonaka, M., Miyazawa, S., 2002. Evolution of the initiating enzymes of the complement system. Genome Biology 3, REVIEWS1001.

Ogden, C.A., deCathelineau, A., Hoffmann, P.R., Bratton, D., Ghebrehiwet, B., Fadok V.A., Henson, P.M., 2001. C1q and mannose binding lectin engagement of cel surface calreticulin and CD91 initiates macropinocytosis and uptake of apoptotic cells. Journal of Experimental Medicine 194, 781-795.

Olesen, H.V., Jensenius, J.C., Steffensen, R., Thiel, S., Schiotz, P.O., 2006. The mannanbinding lectin pathway and lung disease in cystic fibrosis - disfunction of mannan-binding lectin-associated serine protease 2 (MASP-2) may be a major modifier. Clinical Immunology 121, 324-331.

Pagh, R., Duus, K., Laursen, I., Hansen, P.R., Mangor, J., Thielens, N., Arlaud, G.J. Kongerslev, L., Hojrup, P., Houen, G., 2008. The chaperone and potential mannanbinding lectin (MBL) co-receptor calreticulin interacts with MBL through the binding site for MBL-associated serine proteases. FEBS Journal 275, 515-526.

Pavlov, V.I., Skjoedt, M.O., Siow Tan, Y., Rosbjerg, A., Garred, P., Stahl, G.L., 2012 Endogenous and natural complement inhibitor attenuates myocardial injury and arterial thrombogenesis. Circulation 126, 2227-2235.

Ricklin, D., Hajishengallis, G., Yang, K., Lambris, J.D., 2010. Complement: a key system for immune surveillance and homeostasis. Nature Immunology 11 , 785-797.

Rooryck, C., Diaz-Font, A., Osborn, D.P., Chabchoub, E., Hernandez-Hernandez, V., Shamseldin, H., Kenny, J., Waters, A., Jenkins, D., Kaissi, A.A., Leal, G.F., Dallapiccola, B., Carnevale, F., Bitner-Glindzicz, M., Lees, M., Hennekam, R., Stanier, P., Burns, A.J., Peeters, H., Alkuraya, F.S., Beales, P.L., 2011. Mutations in lectin complement pathway genes COLEC11 and MASP1 cause 3MC syndrome. Nature Genetics 43, 197-203.

Rossi, V., Cseh, S., Bally, I., Thielens, N.M., Jensenius, J.C., Arlaud, G.J., 2001. Substrate specificities of recombinant mannan-binding lectin-associated serine proteases-1 and -2. Journal of Biological Chemistry 276, 40880-40887.

Rossi, V., Teillet, F., Thielens, N.M., Bally, I., Arlaud, G.J., 2005. Functional characterization of complement proteases $\mathrm{C}$ 1s/mannan-binding lectin-associated serine protease-2 (MASP-2) chimeras reveals the higher C4 recognition efficacy of the MASP-2 complement control protein modules. Journal of Biological Chemistry 280, 41811-41818.

Sato, T., Endo, Y., Matsushita, M., Fujita, T., 1994. Molecular characterization of a novel serine protease involved in activation of the complement system by mannose-binding protein. International Immunology 6, 665-669.

Schlapbach, L.J., Thiel, S., Kessler, U., Ammann, R.A., Aebi, C., Jensenius, J.C., 2011 Congenital $\mathrm{H}$-ficolin deficiency in premature infants with severe necrotising enterocolitis. Gut 60, 1438-1439.

Schwaeble, W.J., Lynch, N.J., Clark, J.E., Marber, M., Samani, N.J., Ali, Y.M., Dudler, T. Parent, B., Lhotta, K., Wallis, R., Farrar, C.A., Sacks, S., Lee, H., Zhang, M., Iwaki, D. Takahashi, M., Fujita, T., Tedford, C.E., Stover, C.M., 2011. Targeting of mannanbinding lectin-associated serine protease- 2 confers protection from myocardial and gastrointestinal ischemia/reperfusion injury. Proceedings of the National Academy of Sciences of the United States of America 108, 7523-7528.

Sheriff, S., Chang, C.Y., Ezekowitz, R.A., 1994. Human mannose-binding protein carbohydrate recognition domain trimerizes through a triple alpha-helical coiled-coil. Natural Structural Biology 1, 789-794.

Sirmaci, A., Walsh, T., Akay, H., Spiliopoulos, M., Sakalar, Y.B., HasanefendiogluBayrak, A., Duman, D., Farooq, A., King, M.C., Tekin, M., 2010. MASP1 mutations in patients with facial, umbilical, coccygeal, and auditory findings of Carnevale, Malpuech, OSA, and Michels syndromes. American Journal of Human Genetics 87, 679-686.

Skjoedt, M.O., Hummelshoj, T., Palarasah, Y., Honore, C., Koch, C., Skjodt, K., Garred, P., 2010. A novel mannose-binding lectin/ficolin-associated protein is highly expressed in heart and skeletal muscle tissues and inhibits complement activation. Journal of Biological Chemistry 285, 8234-8243.

Skjoedt, M.O., Roversi, P., Hummelshoj, T., Palarasah, Y., Rosbjerg, A., Johnson, S. Lea, S.M., Garred, P., 2012. Crystal structure and functional characterization of the complement regulator mannose-binding lectin (MBL)/ficolin-associated protein-1 (MAP-1). Journal of Biological Chemistry 287, 32913-32921.

Steffensen, R., Thiel, S., Varming, K., Jersild, C., Jensenius, J.C., 2000. Detection of structural gene mutations and promoter polymorphisms in the mannan-binding lectin (MBL) gene by polymerase chain reaction with sequence-specific primers. Journal of Immunological Methods 241, 33-42.

Stengaard-Pedersen, K., Thiel, S., Gadjeva, M., Moller-Kristensen, M Sorensen, R. Jensen, L.T., Sjoholm, A.G., Fugger, L., Jensenius, J.C., 2003. Inherited deficiency of mannan-binding lectin-associated serine protease 2. New England Journal of Medicine 349, 554-560.

Stover, C.M., Thiel, S., Thelen, M., Lynch, N.J., Vorup-Jensen, T., Jensenius, J.C., Schwaeble, W.J., 1999. Two constituents of the initiation complex of the mannan-binding lectin activation pathway of complement are encoded by a single structural gene. Journal of Immunology 162, 3481-3490.

Stuart, L.M., Takahashi, K., Shi, L., Savill, J., Ezekowitz, R.A., 2005. Mannose-binding lectin-deficient mice display defective apoptotic cell clearance but no autoimmune phenotype. Journal of Immunology 174, 3220-3226.

Sugimoto, R., Yae, Y., Akaiwa, M., Kitajima, S., Shibata, Y., Sato, H., Hirata, J., Okochi, K., Izuhara, K., Hamasaki, N., 1998. Cloning and characterization of the Hakata 
antigen, a member of the ficolin/opsonin p35 lectin family. Journal of Biological Chemistry 273, 20721-20727.

Swierzko, A., Lukasiewicz, J., Cedzynski, M., Maciejewska, A., Jachymek, W., Niedziela, T., Matsushita, M., Lugowski, C., 2012. New functional ligands for ficolin-3 among lipopolysaccharides of Hafnia alvei. Glycobiology 22, 267-280.

Takada, F., Takayama, Y., Hatsuse, H., Kawakami, M., 1993. A new member of the C1s family of complement proteins found in a bactericidal factor. Ra-reactive factor, in human serum. Biochemical and Biophysical Research Communications 196, 1003-1009.

Takahashi, M., Ishida, Y., Iwaki, D., Kanno, K., Suzuki, T., Endo, Y., Homma, Y., Fujita, T., 2010. Essential role of mannose-binding lectin-associated serine protease-1 in activation of the complement factor D. Journal of Experimental Medicine 207, 29-37.

Tanio, M., Kondo, S., Sugio, S., Kohno, T., 2007. Trivalent recognition unit of innate immunity system: crystal structure of trimeric human M-ficolin fibrinogen-like domain. Journal of Biological Chemistry 282, 3889-3895.

Teh, C., LE, Y., Lee, H., Lu, J., 2000. M-ficoliln is expressed on monocytes and is a lectin binding to $\mathrm{N}$-acetyl-D-glucosamine and mediates monocyte adhesion and phagocytosis of E. coli. Immunology 101, 225-232.

Teillet, F., Gaboriaud, C., Lacroix, M., Martin, L., Arlaud, G.J., Thielens, N.M., 2008. Crystal structure of the CUB1-EGF-CUB2 domain of human MASP-1/3 and identification of its interaction sites with mannan-binding lectin and ficolins. Journal of Biological Chemistry 283, 25715-25724.

Teillet, F., Lacroix, M., Thiel, S., Weilguny, D., Agger, T., Arlaud, G.J., Thielens, N.M., 2007. Identification of the site of human mannan-binding lectin involved in the interaction with its partner serine proteases: the essential role of Lys55. Journal of Immunology 178, 5710-5716.

Tenner, A.J., Robinson, S.L., Ezekowitz, R.A., 1995. Mannose binding protein (MBP) enhances mononuclear phagocyte function via a receptor that contains the $126,000 \mathrm{M}(\mathrm{r})$ component of the C1q receptor. Immunity 3, 485-493.

Thiel, S., Gadjeva, M., 2009. Humoral pattern recognition molecules: mannanbinding lectin and ficolins. Advances in Experimental Medicine and Biology 653 . 58-73.

Thiel, S., Jensen, L., Degn, S.E., Nielsen, H.J., Gal, P., Dobo, J., Jensenius, J.C., 2012. Mannan-binding lectin (MBL)-associated serine protease-1 (MASP-1), a serine protease associated with humoral pattern-recognition molecules: normal and acute-phase levels in serum and stoichiometry of lectin pathway components. Clinical and Experimental Immunology 169, 38-48.

Thiel, S., Vorup-Jensen, T., Stover, C.M., Schwaeble, W., Laursen, S.B., Poulsen, K. Willis, A.C., Eggleton, P., Hansen, S., Holmskov, U., Reid, K.B., Jensenius, J.C., 1997. A second serine protease associated with mannan-binding lectin that activates complement. Nature 386, 506-510.

Tsujimura, M., Ishida, C., Sagara, Y., Miyazaki, T., Murakami, K., Shiraki, H., Okochi, K., Maeda, Y., 2001. Detection of serum thermolabile beta-2 macroglycoprotein (Hakata antigen) by enzyme-linked immunosorbent assay using polysaccharide produced by Aerococcus viridans. Clinical and Diagnostic Laboratory Immunology 8, 454-459.

Veldhuizen, E.J., van Eijk, M., Haagsman, H.P., 2011. The carbohydrate recognition domain of collectins. FEBS Journal 278, 3930-3941.

Verma, A., White, M., Vathipadiekal, V., Tripathi, S., Mbianda, J., Ieong, M., Qi, L., Taubenberger, J.K., Takahashi, K., Jensenius, J.C., Thiel, S., Hartshorn, K.L., 2012.
Human $\mathrm{H}$-ficolin inhibits replication of seasonal and pandemic influenza A viruses. Journal of Immunology 189, 2478-2487.

Vorup-Jensen, T., Petersen, S.V., Hansen, A.G., Poulsen, K., Schwaeble, W., Sim, R.B., Reid, K.B., Davis, S.J., Thiel, S., Jensenius, J.C., 2000. Distinct pathways of mannan-binding lectin (MBL)- and C1-complex autoactivation revealed by reconstitution of MBL with recombinant MBL-associated serine protease-2. Journal of Immunology 165, 2093-2100.

Wallis, R., Dodds, A.W., Mitchell, D.A., Sim, R.B., Reid, K.B., Schwaeble, W.J., 2007 Molecular interactions between MASP-2, C4, and C2 and their activation fragments leading to complement activation via the lectin pathway. Journal of Biological Chemistry 282, 7844-7851.

Weis, W.I., Drickamer, K., 1994. Trimeric structure of a C-type mannose-binding protein. Structure 2, 1227-1240.

Weis, W.I., Drickamer, K., Hendrickson, W.A., 1992. Structure of a C-type mannose-binding protein complexed with an oligosaccharide. Nature 360 127-134.

Weis, W.I., Kahn, R., Fourme, R., Drickamer, K., Hendrickson, W.A., 1991. Structure of the calcium-dependent lectin domain from a rat mannose-binding protein determined by MAD phasing. Science 254, 1608-1615.

Wittenborn, T., Thiel, S., Jensen, L., Nielsen, H.J., Jensenius, J.C., 2010. Characteristics and biological variations of $\mathrm{M}$-ficolin, a pattern recognition molecule, in plasma. Journal of Innate Immunity 2, 167-180.

Yae, Y., Inaba, S., Sato, H., Okochi, K., Tokunaga, F., Iwanaga, S., 1991. Isolation and characterization of a thermolabile beta-2 macroglycoprotein ('thermolabile substance' or 'Hakata antigen') detected by precipitating (auto) antibody in sera of patients with systemic lupus erythematosus. Biochimica et Biophysica Acta 1078, 369-376.

Yongqing, T., Drentin, N., Duncan, R.C., Wijeyewickrema, L.C., Pike, R.N., 2012 Mannose-binding lectin serine proteases and associated proteins of the lectin pathway of complement: two genes, five proteins and many functions? Biochimica et Biophysica Acta 1824, 253-262.

Ytting, H., Christensen, I.J., Thiel, S., Jensenius, J.C., Svendsen, M.N., Nielsen, L., Lottenburger, T., Nielsen, H.J., 2007. Biological variation in circulating levels of mannan-binding lectin (MBL) and MBL-associated serine protease- 2 and the influence of age, gender and physical exercise. Scandinavian Journal of Immunology $66,458-464$

Zacho, R.M., Jensen, L., Terp, R., Jensenius, J.C., Thiel, S., 2012. Studies of the pattern recognition molecule $\mathrm{H}-$ ficolin: specificity and purification. Journal of Biologica Chemistry 287, 8071-8081.

Zhang, J., Yang, L., Ang, Z., Yoong, S.L., Tran, T.T.T., Anand, G.S., Tan, N.S., Ho, B. Ding, J.L., 2010. Secreted M-ficolin anchors onto monocyte transmembrane G protein-coupled receptor 43 and cross talks with plasma C-reactive protein to mediate immune signaling and regulate host defense. Journal of Immunology 185, 6899-6910.

Zundel, S., Cseh, S., Lacroix, M., Dahl, M.R., Matsushita, M., Andrieu, J.P. Schwaeble, W.J., Jensenius, J.C., Fujita, T., Arlaud, G.J., Thielens, N.M. 2004. Characterization of recombinant mannan-binding lectin-associated serine protease (MASP)-3 suggests an activation mechanism different from that of MASP-1 and MASP-2. Journal of Immunology 172, 4342-4350. 